\title{
Functional characterization and expression analysis of the androgen receptor in zebrafish (Danio rerio) testis
}

\author{
P P de Waal ${ }^{1}$, D S Wang ${ }^{2}$, W A Nijenhuis ${ }^{1}$, R W Schulz $^{1,3}$ and J Bogerd ${ }^{1}$ \\ ${ }^{1}$ Division of Endocrinology and Metabolism, Department of Biology, Faculty of Science, Utrecht University, Padualaan \\ 8, 3584 CH Utrecht, The Netherlands, ${ }^{2}$ School of Life Science, Southwest University, Chongqing 400715, China and \\ ${ }^{3}$ Institute of Marine Research, Research Group Physiology of Reproduction and Growth, PO Box 1870 Nordnes, 5817 \\ Bergen, Norway
}

Correspondence should be addressed to J Bogerd; Email: j.bogerd@uu.nl

\begin{abstract}
The biological activity of androgens, important for male sexual differentiation and development, is mediated by the androgen receptor (AR) that binds to specific DNA recognition sites regulating the transcription of androgen target genes. We investigated androgen production by adult zebrafish testis tissue, and identified 11 1 -hydroxyandrostenedione, 11-ketoandrostenedione (OA), and 11-ketotestosterone (11-KT) as main products, and hence potential ligands, for the zebrafish Ar. These androgens were then included in the pharmacological characterization of the zebrafish Ar. The zebrafish Ar responded well in terms of binding and transactivation to synthetic androgens as well as to testosterone and 11-KT, and reasonably well to OA and androstenedione. In situ hybridization analysis of zebrafish testis revealed that ar mRNA expression was detected in the subpopulation of Sertoli cells contacting early spermatogonia. Reproduction (2008) 136 225-234
\end{abstract}

\section{Introduction}

The androgen receptor (AR) is a member of the nuclear receptor family of proteins that function as ligandactivated transcription factors. The AR mediates the masculinizing effects of androgens on different parts of the reproductive system at different stages of ontogenesis. For example, androgenic sex steroids are involved in male differentiation of the efferent duct system for germ cells (Hannema \& Hughes 2007), spermatogenesis (De Gendt et al. 2004), reproductive behavior, and secondary sexual characteristics (Sato et al. 2004, Soma 2006). The AR shows a widespread expression pattern over different tissues, suggesting a broad spectrum of androgeninduced biological activities. Also in females, androgens are important for reproductive function, as indicated by the folliculogenesis phenotype in female Ar knockout mice (Shiina et al. 2006).

Teleost fish are no exception to this general vertebrate pattern, as exemplified by the effects of androgens on secondary sexual characteristics and behavior (Pall et al. 2002a, 2002b), spermatogenesis (Miura et al. 1991, Cavaco et al. 2001), or Leydig cell androgen production (Cavaco et al. 1999). As regards sex differentiation, fish appear to be particularly sensitive to androgen action, considering that fully functional female-to-male sex reversal can be induced by exposure of juvenile (Baroiller \& Guiguen 2001) and even adult fish
(Kobayashi et al. 1991) to androgens; in some species, sex change is part of the normal life cycle (Baroiller \& Guiguen 2001).

To further our work on zebrafish male sex differentiation and on the development to functional maturity and adult regulation of the two main testicular functions, spermatogenesis and steroidogenesis, and to be able to proceed to studies on the identity and regulation of the expression of AR target genes relevant for these processes, we cloned the full-length zebrafish ar cDNA and studied ar mRNA expression by real-time, quantitative PCR and in situ hybridization. Moreover, we wanted to identify the physiological ligand(s) for the zebrafish Ar in males. In this context, it is important to note that teleost fish express $11 \beta$-hydroxylase (Cyp11b) (Wang \& Orban 2007) and 11 $\beta$-hydroxysteroid dehydrogenase (Hsd11b) (Kusakabe et al. 2006) activities in the testis, so that 11-ketotestosterone (11-KT) is a prominent circulating androgen next to testosterone (T) in many species (Schmidt \& Idler 1962, Borg 1994). Although respective data are not available in zebrafish, a close relative, the common carp (Cyprinus carpio), showed the typical teleost pattern with 11-KT levels being twice as high as the $\mathrm{T}$ levels in the plasma of mature males (Koldras et al. 1990). We have, therefore, analyzed the main androgens produced by zebrafish testis tissue, which were then included in the pharmacological characterization of the zebrafish Ar. Cloning and 
quantitative expression analysis of zebrafish ar have been published also by others (Jørgensen et al. 2007, Hossain et al. 2008) very recently, but these studies did not include a detailed comparison between the ligandbinding characteristics and transactivation properties of the zebrafish Ar. Such a comparison is, however, reported in the present study.

\section{Results \\ Zebrafish ar cDNA cloning, phylogenetic and expression analyses}

The results section describing the full-length zebrafish ar cDNA cloning, the phylogenetic analysis of the zebrafish Ar, and the tissue distribution and ontogeny of zebrafish ar mRNA expression are presented as Supplementary Information, along with Supplementary Figures 1-3, which can be viewed online at www.reproductiononline.org/supplemental/.

\section{Androgen production by zebrafish testis tissue}

To study the steroid specificity and transactivation capacity of the zebrafish $\mathrm{Ar}$ in a targeted manner, we first investigated to which products adult zebrafish testis tissue fragments metabolized $\left.100 \mathrm{nM} \mathrm{[}{ }^{3} \mathrm{H}\right]$-androstenedione $\left(\left[{ }^{3} \mathrm{H}\right]-\mathrm{A} 2\right)$ during $15-$, 30-, or $60-\mathrm{min}$ incubation. Separation of the products by thin layer chromatography showed that the substrate remained largely unconverted in the absence of tissue (Fig. 1A), but a minor impurity of the substrate (Unk-2) was found. In all cases where $\left[{ }^{3} \mathrm{H}\right]$ A2 was incubated with tissue, at least $96 \%$ of the radioactivity co-migrated with known carrier steroids. Densitometry of the autoradiogram showed that the substrate was progressively metabolized with time (Fig. 1B). A major metabolite was $11 \beta$-hydroxyandrostenedione (OHA) that appeared quickly and was prominently present $(11-22 \%)$ at all time points. The pattern of appearance of 11-ketoandrostenedione (OA) differed from that of OHA by showing a steady increase with time from 7 to nearly $27 \%$ of the total product. This pattern was similar to the one of 11-KT except that the latter accumulated at a lower rate (1.5-11\%). Minor products $(<2 \%$ at all time points) were $\mathrm{T}$ and $11 \beta$ hydroxytestosterone $(\mathrm{OHT})$, and $1-2 \%$ of the radioactive products that did not co-migrate with the non-radioactive carrier steroids were assigned to Unk-1 and -3 respectively, while up to $1 \%$ was represented by Unk-2, a minor impurity of the substrate also present in the control incubation without tissue. Taken together, these data suggest that androstenedione (A2) is quickly and effectively metabolized to OHA by Cyp11b activity, before being converted to OA by Hsd11 b activity. OA is further converted to $11-\mathrm{KT}$ by $17 \beta$-hydroxysteroid dehydrogenase (Hsd17b) activity. It appears, however, that neither $\mathrm{OHA}$ nor $\mathrm{A} 2$ are readily accepted as
A
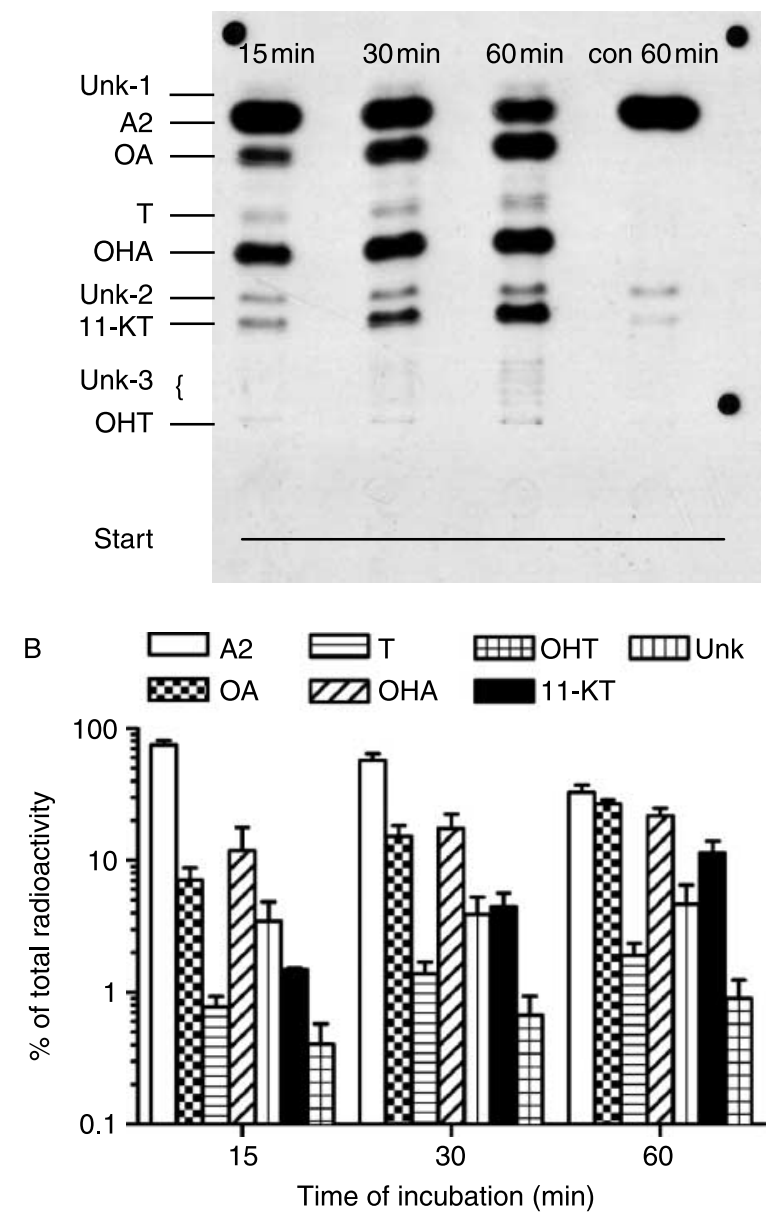

Figure 1 Androgen production in zebrafish testis tissue. (A) Representative autoradiogram of a thin layer chromatogram of dichloromethaneextracted L15 medium containing $\left[{ }^{3} \mathrm{H}\right]-\mathrm{A} 2$ in the presence of zebrafish testis fragments for 15,30 , or $60 \mathrm{~min}$ or in the absence of zebrafish testis fragments for $60 \mathrm{~min}$ (con $60 \mathrm{~min}$ ), after which non-radioactive carrier steroids (androstenedione (A2), 11-ketoandrostenedione (OA), testosterone (T), 11 $\beta$-hydroxyandrostenedione $(\mathrm{OHA}), 11$-ketotestosterone (11$\mathrm{KT}), 11 \beta$-hydroxytestosterone (OHT)) were added. Unk-1, -2, and -3 indicate unknown products. (B) Quantification of densitometrically scanned bands of the autoradiogram (shown in Fig. 1A), representing the steroid metabolites of $\left[{ }^{3} \mathrm{H}\right]-\mathrm{A} 2$ conversion in zebrafish testis tissue; each column represents the average radioactivity ( \pm S.E.M.) for a given metabolite, expressed as percentage of the total amount of radioactivity per lane, determined in three independent experiments.

substrate by the testicular Hsd17b activity, considering that only trace amounts of T or OHT have been found. These results are summarized schematically in Fig. 2.

\section{Ligand-binding characteristics of the zebrafish Ar}

To determine the ligand-binding characteristics of the zebrafish $\mathrm{Ar}$, we first performed saturation ligandbinding assays on human embryonic kidney cell line (HEK 293T cells), transfected with the zebrafish ar expression vector construct, using $\left[{ }^{3} \mathrm{H}\right]$-testosterone $\left.\left({ }^{3} \mathrm{H}\right]-\mathrm{T}\right)$ as a tracer. High-affinity and saturable binding 


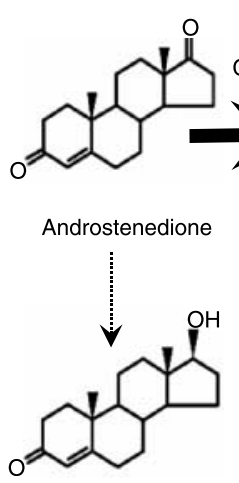

Testosterone

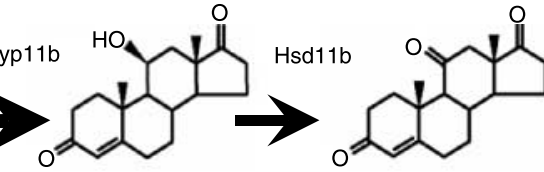

11ß-hydroxyandrostenedione 11-ketoandrostenedione

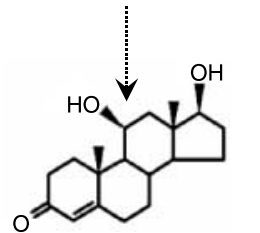

11ß-hydroxytestosterone

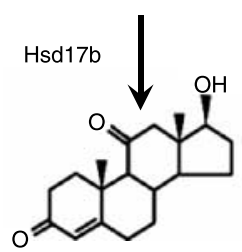

11-ketotestosterone
Figure 2 Schematic representation of steroidogenic processing of androstenedione in zebrafish testis (based on the data shown in Fig. 1). The main products of zebrafish testis are $11 \beta$-hydroxyandrostenedione (OHA), 11-ketoandrostenedione (OA), and 11-ketotestosterone (11$\mathrm{KT})$. The main steroidogenic pathway is indicated by thick arrows. Steroidogenic enzymes indicated are: 11 -hydroxylase (Cyp11b), $11 \beta$ hydroxysteroid dehydrogenase (Hsd11b), and 17 $\beta$-hydroxysteroid dehydrogenase (Hsd17b).

of $\left[{ }^{3} \mathrm{H}\right]-\mathrm{T}$ was observed (Fig. 3A), while no specific binding was observed using non-transfected or mocktransfected cells (data not shown). Our analysis clearly indicated that the zebrafish Ar behaved as a single class of high-affinity $\left[{ }^{3} \mathrm{H}\right]$-T-binding protein with a $K_{d}$ of $1.7 \mathrm{nM}$.

\section{Zebrafish Ar steroid specificity}

To determine the relative affinity of the zebrafish Ar for the most prominent androgens produced in zebrafish testis in comparison with other (synthetic) androgens and nonandrogenic steroids, competitive binding assays were performed, using $2.7 \mathrm{nM}\left[{ }^{3} \mathrm{H}\right]-\mathrm{T}$ as a tracer (Table 1 and Fig. 3B). The curves were parallel, indicating competitive binding between the androgens and $\left[{ }^{3} \mathrm{H}\right]-\mathrm{T}$, allowing $\mathrm{IC}_{50}$ values to be determined and $K_{\mathrm{i}}$ values to be calculated. The zebrafish Ar showed the highest affinity for the two synthetic androgens $17 \alpha$-methyltestosterone (MT) and 17 $\alpha$-dimethyl-19-nortestosterone (mibolerone, MB) (Table 1). Natural androgens, like T and 11-KT, showed nanomolar affinities for the receptor, with $\mathrm{T}$ and $5 \alpha$ dihydrotestosterone (DHT; an important androgen in higher vertebrates, but not produced in fish) showing slightly higher affinities for the receptor than 11-KT. Of the androgenic steroids that are biochemical precursors of 11-KT, A2 had a higher affinity for the zebrafish Ar than OA or OHA. Of the non-androgenic steroids, progesterone $(\mathrm{P})$ and its hydroxylation derivatives (17 $\alpha$-hydroxyprogesterone (OHP) and 17 $\alpha$-hydroxy, 20ß-dihydroprogesterone $\left.\left(\mathrm{OHH}_{2} \mathrm{P}\right)\right)$ showed affinities for the receptor in the high nanomolar range, while $17 \beta$-estradiol $\left(E_{2}\right)$ and cortisol showed clearly lower affinities to the zebrafish Ar.

\section{Transactivation of the zebrafish Ar}

To determine the steroid-induced transactivation properties of the zebrafish Ar, we co-transfected the zebrafish ar expression vector construct together with an androgenregulated reporter vector construct (MMTV-Luc vector, containing the luciferase gene under the control of the mouse mammary tumor virus (MMTV) promoter) into HEK 293T cells (see below). When HEK 293T cells were transfected only with the MMTV-Luc vector, androgens did not increase luciferase activity, indicating that HEK 293T cells do not express endogenous ARs (data not shown).

Dose-dependent, zebrafish Ar-mediated activation of the MMTV promoter was shown for several androgens, e.g., MT, DHT, 11-KT and T (Table 1 and Fig. 3C). The synthetic androgen MT was the most potent steroid for the zebrafish $\operatorname{Ar}\left(\mathrm{EC}_{50}=0.03 \pm 0.01 \mathrm{nM}\right)$, reaching maximal activation at $1 \mathrm{nM}$ (not shown). The main circulating androgens in fish, 11-KT and $\mathrm{T}$, were somewhat less potent in activating the zebrafish $\mathrm{Ar}, \mathrm{T}$ being more potent than 11-KT. A2 and OA showed medium to high nanomolar $\mathrm{EC}_{50}$ as well as $K_{\mathrm{i}}$ values. OHA, albeit showing a certain binding to the zebrafish $\mathrm{Ar}$, was a weak androgen in terms of Ar-mediated transactivation of the MMTV promoter. The $\mathrm{EC}_{50}$ values for all steroids tested are shown in Table 1.

To determine the relative potency of various nonandrogenic steroids to transactivate the MMTV promoter via the zebrafish $\mathrm{Ar}$, they were tested at a fixed concentration of $100 \mathrm{nM}$ (Fig. 3D). The androgens 11-KT and $\mathrm{T}$ (positive controls) induced clear responses, increasing luciferase activity by 32 - and 23-fold respectively. Of the non-androgenic steroids, only $\mathrm{P}$ and $\mathrm{OHH}_{2} \mathrm{P}$ were able to induce small but statistically non-significant increases in luciferase activity, whereas $E_{2}$, cortisol, and OHP were inactive. Hence, the surprisingly low $K_{\mathrm{i}}$ concentrations found for some of the non-androgenic steroids (e.g., $\mathrm{P}, \mathrm{OHH}_{2} \mathrm{P}$ ) were not associated with the capacity to activate the zebrafish Ar. We can conclude that low $K_{\mathrm{i}}$ concentrations only coincide with low $\mathrm{EC}_{50}$ concentrations for activation as well as with effective induction of reporter gene expression in the case of androgens. Among these C19 steroids, the $17 \beta$-hydroxylated configuration was most effective while the status of the C-atom 11 (with or without an oxygen function, viz. T and 11-KT) seemed less relevant. However, when a keto group was present at C-atom 17, the status of $\mathrm{C}$-atom 11 did matter, since androgens with either no oxygen (A2) or a keto group (OA) showed an intermediate affinity and transactivational capacity, while an $11 \beta$-hydroxy group $(\mathrm{OHA})$ further reduced binding affinity and abolished biological activity.

Transactivation of the MMTV promoter via the 11-KTstimulated zebrafish $\mathrm{Ar}$ was inhibited by an AR antagonist. The antagonistic effect of flutamide on the zebrafish Ar-mediated MMTV-promoter transactivation 
via increasing doses of $11-\mathrm{KT}$ (1 $\mathrm{pM}$ to $10 \mu \mathrm{M}$ ) was clearly demonstrated (Fig. 3E), since a 4 - or 60 -fold higher concentration of $11-\mathrm{KT}$ was needed to reach $50 \%$ of the maximal activation with 11-KT in the presence of 1 $\left(\mathrm{EC}_{50}=4.3 \mathrm{nM}\right)$ or $10 \mu \mathrm{M}\left(\mathrm{EC}_{50}=64 \mathrm{nM}\right)$ flutamide respectively, compared with the condition where no flutamide was included ( $\mathrm{EC}_{50}=1.2 \mathrm{nM}$ ).

\section{Localization of ar mRNA in zebrafish testis}

To identify the cell types in zebrafish testis that express ar mRNA, we performed in situ hybridization on $10 \mu \mathrm{m}$ thick cryosections. At low power magnification, a clear signal was observed in discrete cells scattered throughout the testis, in the sections that were hybridized with the antisense cRNA ar probe (Fig. 4A). No signal was observed with the sense cRNA ar probe (Fig. 4B), indicating the specificity of the antisense probe generated against the sequence of zebrafish ar mRNA. At a higher magnification (Fig. 4C), the in situ hybridization signal was observed in the cytoplasm of Sertoli cells, judged by the shape and intratubular position of the
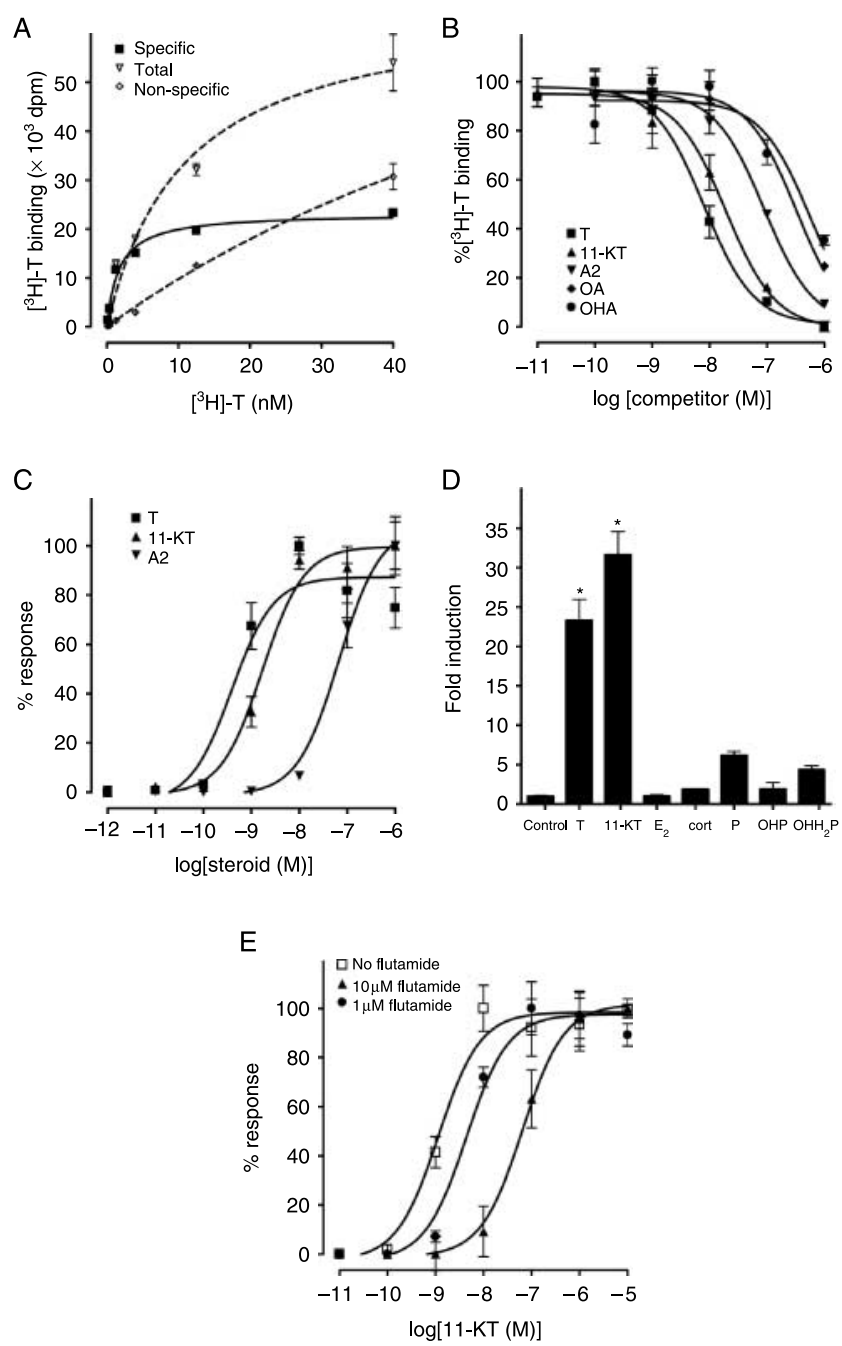

signal. The Sertoli cell is the only intratubular somatic cell type and differs from the germ cells by showing a triangular or kidney-shaped nucleus, in contrast to the round or oval nuclear shape of germ cells. Not all Sertoli cells showed the same level of ar mRNA expression, since only a subset of Sertoli cells were stained (Fig. 4C), compared with the higher number of Sertoli cells lining a tubule in a histological section at the same magnification (see for comparison Fig. 4D). Based on the size, shape, number, and position close to the tubular basement membrane of the germ cells enveloped by the subpopulation of ar mRNA positive Sertoli cells, these germ cells were identified as early spermatogonia present as single cells or in small groups. No clear in situ hybridization signal was observed for peritubular myoid and interstitial Leydig cells (data not shown).

\section{Discussion}

This study describes the cDNA cloning and expression analysis (see Supplementary Information) of the zebrafish ar. Moreover, we identified the physiologically relevant androgens, produced in the zebrafish testis, and included these - together with other steroids - in the functional characterization of the zebrafish Ar.

Figure 3 Binding and transactivation analysis of the zebrafish Ar. (A) Saturation analysis of zebrafish Ar. HEK 293T cells were transfected with the zebrafish ar expression vector construct and incubated with increasing amounts of $\left[{ }^{3} \mathrm{H}\right]-\mathrm{T}$ in the presence or absence of a 1000-fold excess of unlabeled T. Total, non-specific, and specific $\left[{ }^{3} \mathrm{H}\right]-\mathrm{T}$ binding are shown. (B) Competitive binding analysis of the zebrafish Ar. HEK 293T cells were transiently transfected with the zebrafish ar expression vector construct, and incubated with $\left[{ }^{3} \mathrm{H}\right]-\mathrm{T}$ as a tracer in the absence (not shown) or presence of increasing concentrations (10 pM to $1 \mu \mathrm{M}$ ) of various androgens. (C) Ligand-induced transactivation properties of the zebrafish Ar. HEK 293T cells were transiently co-transfected with the MMTV-luciferase vector together with the zebrafish ar expression vector construct. The cells were incubated with increasing concentrations of various androgens ( $1 \mathrm{pM}$ to $10 \mu \mathrm{M})$. (D) Ligand-induced, zebrafish Ar-mediated transactivation of the MMTV promoter at a fixed concentration of $100 \mathrm{nM}$ of various steroids. As a control, the ratio of the fold induction of $\mathrm{OHA}$ at $100 \mathrm{nM}$ (no appreciable induction observed) divided by the fold induction of OHA at $1 \mathrm{pM}$ (no active ligand) is given. In addition, OHA has a very low affinity for the zebrafish Ar. Each column represents the mean ratio of luciferase activity at $100 \mathrm{nM}$ of the steroid divided by the luciferase activity at $1 \mathrm{pM}$ of $\mathrm{OHA}$ of three independent experiments, with the vertical bars representing the S.E.M. Lack of error bars is due to the errors being too small to show graphically. Asterisks represent fold induction significantly different from control, $P<0.001$, using one-way ANOVA with Newman-Keuls post test. (E) Inhibition of 11-KT-induced, zebrafish Ar-mediated transactivation of the MMTV promoter by flutamide. The cells were incubated for $24 \mathrm{~h}$ with increasing concentrations of 11-KT $(1 \mathrm{pM}$ to $10 \mu \mathrm{M})$ with or without $1 \mu \mathrm{M}$ or $10 \mu \mathrm{M}$ flutamide. Percentage (\%) of response: values are given relative to the maximal amount of luciferase activity for each condition. Each point (Fig. 3B, C, and E) represents the mean \pm s.E.M. of three independent experiments. Curves were generated using non-linear regression (GraphPad Prism 4.0). 
Table 1 Comparison of ligand competition data and transactivation data of the zebrafish Ar.

\begin{tabular}{|c|c|c|c|c|}
\hline \multicolumn{2}{|c|}{ Competitive binding } & \multicolumn{3}{|c|}{ Transactivation } \\
\hline Steroid & $K_{\mathrm{i}}(\mathrm{nM})$ & Steroid & $\mathrm{EC}_{50}(\mathrm{nM})$ & $\begin{array}{l}\text { Max. fold } \\
\text { induction }\end{array}$ \\
\hline MT & $0.73 \pm 0.20$ & MT & $0.03 \pm 0.01$ & $40.81 \pm 3.93$ \\
\hline $\mathrm{MB}$ & $0.82 \pm 0.01$ & DHT & $0.13 \pm 0.04$ & $39.69 \pm 2.22$ \\
\hline DHT & $1.65 \pm 1.55$ & $\mathrm{~T}$ & $0.42 \pm 0.20$ & $39.33 \pm 4.64$ \\
\hline$\left[{ }^{3} \mathrm{H}\right]-\mathrm{T}\left(K_{\mathrm{d}}\right.$ value $)$ & $1.70 \pm 0.50$ & $11-\mathrm{KT}$ & $1.16 \pm 0.60$ & $43.70 \pm 2.52$ \\
\hline $\mathrm{OHH}_{2} \mathrm{P}$ & $4.64 \pm 2.80$ & MB & $1.63 \pm 2.79$ & $34.86 \pm 3.79$ \\
\hline $11-\mathrm{KT}$ & $4.77 \pm 2.26$ & $\mathrm{OA}$ & $50.8 \pm 34.7$ & $36.38 \pm 5.01$ \\
\hline $\mathrm{P}$ & $6.99 \pm 1.61$ & $\mathrm{~A} 2$ & $58.0 \pm 31.1$ & $16.84 \pm 4.17$ \\
\hline A2 & $19.6 \pm 1.84$ & $\mathrm{OHH}_{2} \mathrm{P}$ & $116 \pm 103$ & $8.44 \pm 2.19$ \\
\hline $\mathrm{OHP}$ & $21.8 \pm 1.34$ & $\mathrm{P}$ & $467 \pm 615$ & $4.50 \pm 1.61$ \\
\hline$E_{2}$ & $71.6 \pm 96.7$ & $\mathrm{OHP}$ & $951 \pm 1543$ & $4.50 \pm 1.46$ \\
\hline OA & $71.7 \pm 5.24$ & Cortisol & $185 \overline{5} \pm 702$ & $10.07 \pm 2.55$ \\
\hline $\mathrm{OHA}$ & $128 \pm 24.0$ & $\mathrm{OHA}$ & ND & $2.16 \pm 0.26$ \\
\hline Cortisol & $352 \pm 162$ & $E_{2}$ & ND & $1.87 \pm 0.26$ \\
\hline
\end{tabular}

$K_{\mathrm{i}}$ values (nM) of several steroids for the zebrafish $\mathrm{Ar}$ are given. For reference, the $K_{d}$ value of radiolabeled testosterone $\left(\left[{ }^{3} \mathrm{H}\right]-\mathrm{T}\right)$ is also included. The zebrafish Ar was expressed in HEK 293T cells and $\left[{ }^{3} \mathrm{H}\right]-\mathrm{T}$ was used as tracer. $K_{\mathrm{i}}$ values represent average \pm s.E.M. of three independent experiments. $\mathrm{EC}_{50}$ values of ligand-induced Ar transactivation of the MMTV promoter are also shown. Luciferase activity was measured after incubation with increasing concentrations of various steroid hormones ( $1 \mathrm{pM}$ to $10 \mu \mathrm{M})$. $\mathrm{EC}_{50}$ values represent average \pm S.E.M. of three independent experiments.

In the present study, a positive ar in situ hybridization signal was detected in a subpopulation of Sertoli cells in zebrafish testis. The majority of Sertoli cells, however, remained unlabeled, indicating that not all Sertoli cells have the same level of ar mRNA expression. Spermatogenesis in zebrafish, as in all other fish and amphibians, occurs within spermatogenic cysts. The cysts are formed when Sertoli cells envelop a germ cell clone by cytoplasmic extensions. Within each cyst, germ cell development occurs synchronously and different cysts contain clonal lines of germ cells at different developmental stages (for review, see Schulz \& Miura 2002). From our evaluation of the morphology and position of the germ cells surrounded by the zebrafish ar mRNA-positive subpopulation of Sertoli cells, we conclude that Sertoli cells in contact with early spermatogonia express the highest levels of ar mRNA in zebrafish testis. Interestingly, testicular explants from immature Japanese eel (Anguilla japonica) containing only early spermatogonia responded to incubations with 11-KT by showing full spermatogenesis (Miura et al. 1991), starting with several rounds of rapid proliferation of spermatogonia. A high level of expression of ar mRNA in Sertoli cells surrounding early spermatogonia would be consistent with the notion that these Sertoli cells are the target of stimulatory effects of $11-\mathrm{KT}$, resulting in a stimulation of spermatogonial proliferation and differentiation (Miura \& Miura 2001). Likewise, the level of Ar protein in the zone of the salamander testis that contains predominantly spermatogonia was 1.5 - to 5 -fold higher than in zones containing further advanced germ cell types (Singh \& Callard 1992). Future work has to demonstrate whether 11-KT has similar effects on zebrafish spermatogenesis as in Japanese eel, and whether progress of spermatogenesis beyond the stage of early spermatogonia is associated with a downregulation of ar mRNA levels in the Sertoli cells contacting later germ cell stages. Although in mammalian testis a particular Sertoli cell supports germ cells in different stages of development simultaneously, differences in Ar mRNA levels among Sertoli cells that depend on the stage of the seminiferous epithelial cycle have been described in rat (Shan et al. 1995). In the same study, Ar mRNA has been detected in Leydig cells and peritubular myoid cells, albeit at much lower levels than in Sertoli cells at adulthood. In the present study no prominent positive in situ hybridization signal was found
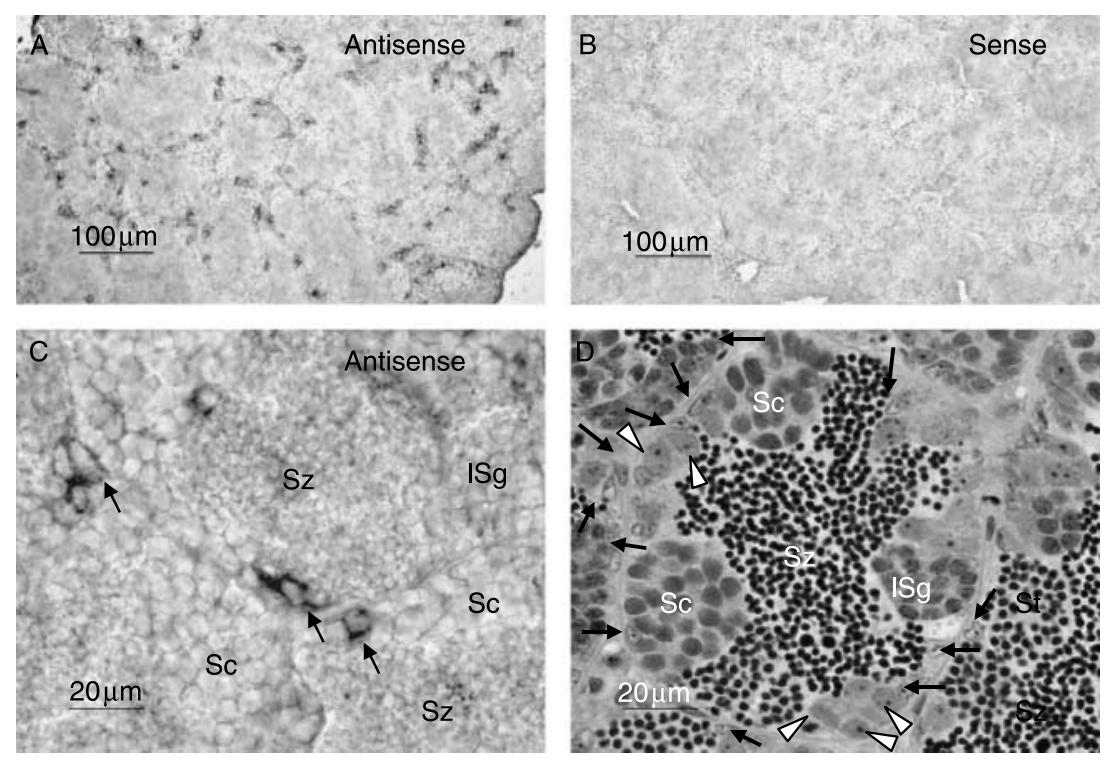

Figure 4 In situ hybridization analysis of ar mRNA localization in zebrafish testis. Lower magnification $(10 \times)$ of a $10 \mu \mathrm{m}$ cryosection of zebrafish testis, hybridized with (A) the ar antisense cRNA probe, showing signal in discrete cells, and (B) the ar sense cRNA probe, showing no aspecific signal. Higher magnification $(60 \times)$ of a cryosection of zebrafish testis, hybridized with (C) the ar antisense cRNA probe, revealed staining in the cytoplasm of a subpopulation of Sertoli cells. (D) Resinembedded histological section $(4 \mu \mathrm{m})$ stained with toluidine blue shows the position of different germ cell stages and Sertoli cells. Indicated are the nuclei of Sertoli cells (arrows) and early spermatogonia (arrowheads), while late spermatogonia are indicated with ISg, spermatocytes by Sc, spermatids by St, and spermatozoa by $\mathrm{Sz}$ (in $\mathrm{C}$ and D). Scale bars are shown in each panel. 
in somatic cell types other than Sertoli cells, indicating that the levels of armRNA in Leydig cells and peritubular myoid cells in zebrafish testis are too low to be detected by the present in situ hybridization approach.

Naturally occurring androgens as well as synthetic androgens are potential ligands for ARs. Our studies suggest that $\mathrm{OHA}, \mathrm{OA}$, and $11-\mathrm{KT}$ are the major $\mathrm{A} 2$ metabolites of the adult zebrafish testis. Although we did not study the production of $A 2$, it seems unlikely that this steroid is a quantitatively important end product of the zebrafish testis, viz. its rapid and effective conversion to OHA. Considering the low affinity and marginal transactivational capacity of $\mathrm{OHA}$, it is unlikely to be a relevant AR ligand in zebrafish. However, OA and in particular 11-KT accumulate at the end of the biosynthetic chain and show respectively reasonable and high binding affinity and transactivation properties. We propose to consider 11-KT as the physiologically most important androgen of the group of 11-oxygenated steroids produced by zebrafish testis, in particular because 11-KT holds the most downstream position in the steroidogenic pathway. In closely related species, such as goldfish (Carassius auratus; Abdullah \& Kime 1994) or common carp (Barry et al. 1990), 11-oxygenated teleost androgens have been identified as main products of testicular steroidogenesis, such as 11-KT in goldfish, or $\mathrm{OA}$ in common carp, which can either be converted to $11-\mathrm{KT}$ by $\mathrm{Hsd} 17 \mathrm{~b}$ activity residing in erythrocytes of many fish species (Mayer et al. 1990), or is directly produced by carp testis tissue with an efficiency increasing during pubertal maturation (Consten et al. 2002), suggesting that an increasing Hsd $17 \mathrm{~b}$ activity (i.e., conversion of OA to $11-\mathrm{KT}$ ) is one of the factors associated with puberty. A testicular $h s d 17 b$ type 3 cDNA has been identified recently in zebrafish (Mindnich et al. 2005), which converted OA to 11-KT. Although the same enzyme also has the catalytic capacity to convert OHA to OHT and A2 to T when transfected into a cell line (Mindnich et al. 2005), these conversions are not occurring to a noteworthy degree in zebrafish testis tissue fragments. A possible explanation may be the competition for the substrates in the primary tissue culture: we showed that $\mathrm{A} 2$ is rapidly converted to OHA by Cyp $11 \mathrm{~b}$ activity, possibly restricting the $\mathrm{A} 2$ to $\mathrm{T}$ conversion, while Hsd17b-mediated conversion of $\mathrm{OHA}$ to $\mathrm{OHT}$ may be hampered by the Hsd11b-catalyzed conversion of $\mathrm{OHA}$ to $\mathrm{OA}$.

The very low levels of T production in zebrafish testis tissue may seem surprising, also considering that circulating levels of $\mathrm{T}$ reach $\sim 50 \%$ of those of $11-\mathrm{KT}$ in adult male carp (Koldras et al. 1990). However, a similar situation has been described in African catfish (Clarias gariepinus) where the testicular production of $\mathrm{T}$ is at least 200-fold lower than one of the 11-oxygenated androgens (Vermeulen et al. 1994), while T plasma levels are in the same order of magnitude as 11-KT (Schulz et al. 1994). The possibility that circulating $\mathrm{T}$ might be derived from extra-testicular sources was excluded for the catfish (Vermeulen et al. 1994) since castration decreased T plasma levels below the detection limits. We therefore speculate that the relatively high $\mathrm{T}$ plasma levels reflect the high-affinity and high-capacity binding of $\mathrm{T}$ to sex steroid-binding globulin (SBG), protecting $\mathrm{T}$ from rapid breakdown and thereby prolonging its biological halflife time. An SBG-like protein has been identified in zebrafish (Miguel-Queralt et al. 2004), and steroidbinding characteristics have been studied in a number of species, including the close zebrafish relatives goldfish (Pasmanik \& Callard 1986) and carp (Chang \& Lee 1992), showing that $\mathrm{T}$ (and $\mathrm{E}_{2}$ ) but not 11-KT are bound with high affinity and capacity.

While no information on circulating androgens is available in zebrafish, respective data have been published from closely related bigger species. In common carp, 11-KT and $T$ were quantified at different stages of the reproductive cycle, and the concentrations varied between 3-6 and 1.5-2.5 ng/ml respectively (Koldras et al. 1990). In goldfish (Rosenblum et al. 1985), 11-KT and T levels varied at different stages of testis development between 0.5-8.5 and $0.6-10 \mathrm{ng} / \mathrm{ml}$ respectively. Taking the above consideration and our pharmacological and steroidogenesis data, we conclude that 11-KT is likely to be the main androgen in adult male zebrafish, while $\mathrm{T}$ may fulfill specific roles as well. As regards the $K_{\mathrm{d}}, K_{\mathrm{i}}$, and $\mathrm{EC}_{50}$ values for $11-\mathrm{KT}$ in the range of 2-5 $\mathrm{nM}$ (see below), the plasma concentrations of 11-KT ranging from 0.5 to $10 \mathrm{ng} / \mathrm{ml}$ - i.e., $1.5-30 \mathrm{nM}$ - in male carp and goldfish would be well suited to activate the Ar in zebrafish.

We have shown that the zebrafish Ar is a functional AR, which is supported by high-affinity androgenbinding and androgen-dependent transactivational capacity. Comparison of the ligand-binding and transactivation properties of the zebrafish Ar revealed that steroids with a high affinity for the receptor (i.e., $M T, M B$, $\mathrm{DHT}, \mathrm{T}, \mathrm{OHH}_{2} \mathrm{P}$, and 11-KT) also gave a high induction of zebrafish Ar-mediated transactivation. The exception is $\mathrm{OHH}_{2} \mathrm{P}$, which could only induce transactivation in the high nanomolar range.

Similar binding affinities for the zebrafish Ar have been obtained by Jørgensen et al. (2007) for DHT, 11-KT, T, and A2. In the regard of high-affinity binding to synthetic androgens as well as 11-KT, T, and DHT, the zebrafish $\mathrm{Ar}$ protein is similar to a number of other piscine Ar proteins cloned from rainbow trout (Oncorhynchus mykiss; i.e., Ara; Takeo \& Yamashita 2000), fathead minnow (Pimephales promelas; Wilson et al. 2004), and threespined stickleback (Gasterosteus aculeatus; Olsson et al. 2005). Studies on androgen binding to tissues extracts indicated that in some species two distinct patterns of androgen binding were found - one with rather specific binding of $\mathrm{T}$ and the other more similar to the broader specificity found for the zebrafish Ar in the present study. Binding of a broad range of synthetic and natural androgens, as found for the zebrafish Ar, was shared by 
one of the Ar types present in Atlantic croaker (Micropogonias undulatus; Sperry \& Thomas 1999) and coho salmon (O. kisutch; Fitzpatrick et al. 1994) gonad tissue.

The transactivation properties of zebrafish Ar relate well to those of rainbow trout Ara, which did not distinguish between T and 11-KT (Takeo \& Yamashita 2000). Transactivation studies with both Japanese eel Ar proteins using a fixed concentration $(100 \mathrm{nM})$ of the steroids tested) revealed that $11-\mathrm{KT}, \mathrm{DHT}, \mathrm{MB}$, and $\mathrm{MT}$ were the most potent steroids in terms of transactivation of eel Ara (Todo et al. 1999), and 11-KT, MB, and MT of eel Arb (Ikeuchi et al. 1999).

Data on zebrafish Ar transactivation, but not on receptor binding, have been reported very recently (Hossain et al. 2008) with regard to five androgens we have studied as well, however, using a zebrafish liver cell line. While similar data have been obtained as regards the two main androgens (11-KT and T), $\mathrm{EC}_{50}$ values for MT and DHT were reported to be $\sim 100$-fold lower than the results presented here, while A2 that we found to have reasonable transactivation activity was reported to be inactive. The relatively low activity of DHTand MT does not appear to be in line with the studies that reported on the transactivation profiles of other fish Ar proteins (Ikeuchi et al. 1999, Todo et al. 1999, Takeo \& Yamashita 2000). Moreover, the wellestablished use of MT as a compound to induce femaleto-male sex reversal in zebrafish research (Westerfield 2000) or salmonid aquaculture (Donaldson \& Hunter 1982) provides evidence for the biological activity of this compound. It also seems important to note that Hossain et al. (2008), when modeling the zebrafish Ar-binding site to calculate the interaction energy between $\mathrm{Ar}$ and different ligands, reported that DHT and A2 showed interaction energies similar to 11-KT.

The pharmacological characterization of Ar subtypes from the different species (Ikeuchi et al. 1999, Todo et al. 1999, Takeo \& Yamashita 2000, Wilson et al. 2004, Olsson et al. 2005) does not show sufficient overlap to draw a general conclusion at present, because of differences in experimental set up (i.e., the use of different cell lines, different tracers, and different promoter-reporter constructs). Taken together, however, it seems that the zebrafish Ar described here groups well with $\mathrm{Ar}$ proteins characterized in fathead minnow, rainbow trout (i.e., Ara), Japanese eel (both Ara and Arb), and Atlantic croaker (type $2 \mathrm{Ar}$ ), presenting a broad androgen-binding specificity.

In summary, we found a single gene coding for a nuclear $\mathrm{Ar}$ in the zebrafish, and no indications exist for another ar gene in the zebrafish genome. A similar conclusion, supported by Southern blot analysis, has been drawn by Hossain et al. (2008). The zebrafish ar mRNA is expressed in all tissues examined and our in situ hybridization studies revealed that high levels of expression in adult testis are found in the subpopulation of Sertoli cells that contact early spermatogonia.
Furthermore, the receptor has been characterized in vitro to respond well in terms of binding as well as transactivation to $11-\mathrm{KT}$ and $\mathrm{T}$, two natural androgens proposed to be the physiologically most relevant androgens in zebrafish. The pharmacological characteristics and the tissue distribution pattern of the zebrafish Ar will allow us to further study the role of this receptor in male sex differentiation and spermatogenesis.

\section{Materials and Methods}

The material and methods section describing the cloning of the full-length zebrafish ar cDNA, the phylogenetic analysis of the zebrafish Ar as well as the real-time, quantitative PCR analysis of zebrafish ar tissue distribution and ontogeny are presented as Supplementary Information, which can be viewed online at www.reproduction-online.org/supplemental/.

\section{Animals and source of steroid hormones}

Zebrafish (Danio rerio; Tübingen $\mathrm{AB}$ strain) were kept at a $12 \mathrm{~h}$ light:12 h darkness cycle under standard conditions (Westerfield 2000). Animal culture and handling was consistent with the Dutch national regulations; the Life Science Faculties Committee for Animal Care and Use approved the experimental protocols.

All non-radioactive steroids and the AR antagonist flutamide were purchased from Sigma-Aldrich. Steroids used in this study were T, 11-KT, MT, MB, A2, OA, OHA, OHT, DHT, E2, P, OHP, $\mathrm{OHH}_{2} \mathrm{P}$, and cortisol.

\section{Zebrafish ar expression vector construct, cell lines, and transfections}

The full-length open-reading frame of the zebrafish ar was PCR amplified using primers 1943 and 1944 (Supplementary Table 1, which can be viewed online at www.reproductiononline.org/supplemental/), cloned into pcDNA3.1/V5-His TOPO vector (Invitrogen), and the insert was sequence verified by DNA sequence analysis.

Since zebrafish is a small species (body weight of an adult male $\sim 0.5 \mathrm{~g}$ ), it is not feasible to perform ligand-binding studies on target tissue homogenates. Therefore, HEK 293T cells (DuBridge et al. 1987) were used to express the zebrafish ar. HEK 293T cells were grown in Dulbecco's modified Eagle's medium (DMEM) supplemented with $10 \% \mathrm{v} / \mathrm{v}$ fetal bovine serum (FBS), non-essential amino acids, glutamine, and penicillin/streptomycin (all from Gibco) at $37^{\circ} \mathrm{C}$ in a $\mathrm{CO}_{2}$ incubator. The cells were transfected using a standard calcium phosphate precipitation method (Graham \& Van der Eb 1973).

\section{Binding assay}

For saturation ligand-binding analysis, HEK 293T cells were seeded in $10 \mathrm{~cm}$ dishes $\left(\sim 1 \times 10^{6}\right.$ cells per dish) and after $24 \mathrm{~h}$ co-transfected with $0.1,1$, or $6 \mu$ g zebrafish ar expression vector construct and up to $11 \mu \mathrm{g}$ carrier plasmid. One day after transfection, the cells were transferred to 24 -well plates, coated 
with poly-L-lysine hydrobromide (Sigma-Aldrich). Two days after the transfer, the cells were incubated for $2 \mathrm{~h}$ with binding assay medium (DMEM without phenol red, supplemented with glutamine, non-essential amino acids, and charcoal-stripped $0.2 \% \mathrm{v} / \mathrm{v}$ FBS (to remove any steroids originating from the FBS)) at $37^{\circ} \mathrm{C}$. Then, radioactive tracer $\left(\left[{ }^{3} \mathrm{H}\right]-\mathrm{T}\right.$; specific activity $77.0 \mathrm{Ci} / \mathrm{mmol}$; Perkin-Elmer, Waltham, MA, USA) was added, either alone or in the presence of $1 \mu \mathrm{M}$ unlabeled $\mathrm{T}$, dissolved in binding medium. After 90-min incubation at room temperature, the cells were quickly washed twice with ice-cold PBS to remove unbound tracer. The cells were harvested in $200 \mu \mathrm{l}$ sodium hydroxide $(1 \mathrm{M})$ per well and radioactivity was counted in a $\beta$-counter (Packard 1900 TR liquid scintillation counter; Packard Instruments, Meriden, CT, USA). Specific $\left[{ }^{3} \mathrm{H}\right]-\mathrm{T}$ binding over a range of increasing concentrations was calculated by subtracting non-specific binding (binding of tracer in the presence of unlabeled T) from total binding (binding of tracer in the absence of unlabeled T); in all cases, bound $\left[{ }^{3} \mathrm{H}\right]-\mathrm{T}$ could be displaced by increasing concentrations of unlabeled $\mathrm{T}$ (data not shown). Pilot experiments with HEK 293T cells, transfected with various amounts of zebrafish ar expression vector construct, revealed that the zebrafish Ar displayed nanomolar affinity for [ $\left.{ }^{3} \mathrm{H}\right]-\mathrm{T}$ (data not shown); in all other experiments, including the ligand competition assays (see below), HEK 293T cells were transfected with $1 \mu \mathrm{g}$ zebrafish ar expression vector construct and $10 \mu \mathrm{g}$ carrier plasmid. Binding remained unchanged over a period up to $8 \mathrm{~h}$, indicating that $\left[{ }^{3} \mathrm{H}\right]-\mathrm{T}$ is not metabolized in HEK 293T cells (data not shown). Moreover, both non-transfected and mocktransfected HEK 293T cells did not show any specific binding of $\left[{ }^{3} \mathrm{H}\right]-\mathrm{T}$ (data not shown). Non-linear curve fitting procedures (GraphPad PRISM 4.0; GraphPad Software Inc.; San Diego, CA, USA) were used to calculate the $K_{\mathrm{d}}$.

\section{Ligand competition assay}

To determine the affinity of other steroids for the zebrafish Ar, HEK 293T cells transfected with the zebrafish ar expression vector construct were incubated with increasing concentrations (10 pM to $1 \mu \mathrm{M})$ of each steroid, mixed with tracer $\left(\left[{ }^{3} \mathrm{H}\right]-\mathrm{T}\right.$; final concentration $2.7 \mathrm{nM}$ ) at room temperature, followed by measurement of tracer binding to the transfected cells. The $\mathrm{IC}_{50}$ values were calculated with non-linear regression (GraphPad PRISM 4.0). To allow the calculation of $K_{\mathrm{i}}$ values from $\mathrm{IC}_{50}$ values, a dose-response curve of non-labeled testosterone was included in each experiment. Assuming that ARs possess the same affinity for $\mathrm{T}$ and $\left[{ }^{3} \mathrm{H}\right]-\mathrm{T}, K_{\mathrm{i}}$ values were calculated using the formula: $K_{\mathrm{i}}=\left(\mathrm{IC}_{50}\right.$ steroid//C $\left.\mathrm{C}_{50} \mathrm{~T}\right) \times K_{\mathrm{d}}\left[{ }^{3} \mathrm{H}\right]-\mathrm{T}$.

\section{Transactivation assay}

HEK 293T cells were seeded in $10 \mathrm{~cm}$ dishes $\left(\sim 1.25 \times 10^{6}\right.$ cells per dish). After $24 \mathrm{~h}$, the cells were co-transfected with $500 \mathrm{ng}$ zebrafish ar expression plasmid and $10 \mu \mathrm{g}$ of MMTVLuc plasmid (Stocklin et al. 1996). After 1 day, the cells were transferred to 24-well plates coated with poly-L-lysine hydrobromide (Sigma-Aldrich). The next day, the medium was replaced with transactivation assay medium (DMEM without phenol red, supplemented with charcoal-stripped $0.2 \% \mathrm{v} / \mathrm{v}$ FBS, glutamine, and non-essential amino acids) containing steroid at end concentrations ranging between $1 \mathrm{pM}$ and $1 \mu \mathrm{M}$. After $24-36 \mathrm{~h}$ of incubation at $37^{\circ} \mathrm{C}$, the cells were harvested in lysis mix (100 mM potassium phosphate $(\mathrm{pH} 7.7), 1 \% \mathrm{v} / \mathrm{v}$ Triton X-100 (Sigma-Aldrich), 15\% v/v glycerol, and $2 \mathrm{mM}$ dithiotreitol (DTT)) and stored at $-80{ }^{\circ} \mathrm{C}$. Luciferase activity was determined by adding an equal volume of substrate mix (100 mM potassium phosphate ( $\mathrm{pH} 7.7), 250 \mathrm{mM}$ D-luciferin (Invitrogen), $1 \mathrm{mM}$ DTT, $2 \mathrm{mM}$ ATP (Roche) and $15 \mathrm{mM}$ magnesium sulfate (Promega)) to thawed samples and luminescence was measured in a Perkin-Elmer luminometer.

\section{Analysis of androgen production in zebrafish testis}

Except for a study on the production of steroid glucuronides and their possible role as pheromones (Van den Hurk et al. 1987), no information has been published on the identity of the main androgenic steroids produced by adult zebrafish testis tissue. To address this caveat, the following experiment was performed in triplicate: testis tissue was collected from eight adult males $(28.7 \pm 3.6 \mathrm{mg}$ total wet weight). Each testis was divided into two fragments, and the tissue fragments were pooled, rinsed with L15 medium, and transferred into $2 \mathrm{ml} \mathrm{L15}$ medium containing tritiated A2 (7-[ $\left.{ }^{3} \mathrm{H}\right]-\mathrm{A} 2$; specific activity $24.5 \mathrm{Ci} / \mathrm{mmol}$; NET1001, NEN Dupont, Boston, MA, USA) at a final concentration of 100 nM. After 15-, 30-, and 60-min incubation at $28^{\circ} \mathrm{C}$ in a gently shaking waterbath ( 5 revolutions per $\mathrm{min}$ ), $0.25 \mathrm{ml}$ medium was removed, added to a tube containing a mixture of $5 \mu$ l of each of the following non-radioactive carrier steroids $(20 \mu \mathrm{g} / \mathrm{ml}$ ethanol): T, A2, OHA, OHT, OA, and 11-KT. Steroids were immediately extracted twice with $0.5 \mathrm{ml}$ dichloromethane. The two aliquots of dichloromethane were combined, evaporated, and the extracts were transferred, dissolved in a few drops of ethanol, to thin layer chromatography plates $(10 \times 10 \mathrm{~cm}$ HPTLC silica-coated glass plates with a $10 \times 2.5 \mathrm{~cm}$ concentrating zone; Merck). The plates were first developed in toluene:cyclohexane $=1: 1$ to concentrate the samples, and steroids were then separated by developing the plate with chloroform:ethanol=95:5. The non-radioactive carrier steroids, added just before extraction, were localized under u.v. light at $254 \mathrm{~nm}$. The plate was then treated with a scintillation spray (En ${ }^{3}$ hance Spray, NEN Dupont), and radioactivity was localized as photons using Hyperfilm MP (Amersham Life Science). To relate bands on the film to the amount of radioactivity associated with the different fractions, the bands were quantified densitometrically using a PC-based image analysis system, using a program developed in the KS400 version 3.0 software package (Carl Zeiss Vision, Göttingen, Germany). Results are expressed as percentage of the total amount of radioactivity of the respective sample. Steroids were identified by co-migration with non-radioactive carrier steroids that were visualized under u.v. light.

\section{In situ hybridization}

A zebrafish ar-specific PCR product was generated with primers 2430 and 2431 (see Supplementary Table 1). The $\sim 465$ bp PCR product was gel purified, and served as a template for digoxigenin-labeled cRNA probe synthesis, as described previously (Vischer et al. 2003). 
Zebrafish testes were dissected and fixed in $4 \% \mathrm{w} / \mathrm{v}$ paraformaldehyde in PBS, immersed in $25 \% \mathrm{w} / \mathrm{v}$ sucrose at $4{ }^{\circ} \mathrm{C}$ for $16 \mathrm{~h}$, and then frozen in Neg-50 frozen section medium (Richard Allen Scientific, Kalamazoo, MI, USA). The protocol used for in situ hybridization was previously described (Weltzien et al. 2003) with the following modifications. Cryostat sections were cut at $10 \mu \mathrm{m}$ thickness, and probe was added in a final concentration of $800 \mathrm{ng} / \mathrm{ml}$. After staining, sections were rinsed in $96 \%$ ethanol for $40 \mathrm{~s}$ and in MilliQ water for $15 \mathrm{~min}$, before mounting in Aquamount (Merck).

\section{Declaration of interest}

The authors declare that there is no conflict of interest that would prejudice their impartiality.

\section{Funding}

The research was funded by an intramural PhD student grant from the Department of Biology, Utrecht University.

\section{Acknowledgements}

The authors thank Wytske van Dijk and Joke Granneman (both Division Endocrinology and Metabolism) for their technical assistance with the androgen metabolism experiments.

\section{References}

Abdullah MAS \& Kime DE 1994 Increased substrate concentration causes a shift from production of 11-oxygenated androgens to 17,20-dihydroxyprogestogens during the in vitro metabolism of 17-hydroxyprogesterone by goldfish testes. General and Comparative Endocrinology 96 129-139.

Baroiller JF \& Guiguen Y 2001 Endocrine and environmental aspects of sex differentiation in gonochoristic fish. EXS 91 177-201.

Barry TP, Aida K, Okumura T \& Hanyu I 1990 The shift from C-19 to C-21 steroid synthesis in spawning male common carp, Cyprinus carpio, is regulated by the inhibition of androgen production by progestogens produced by spermatozoa. Biology of Reproduction 43 105-112.

Borg B 1994 Androgens in teleost fishes. Comparative Biochemistry and Physiology Part C: Comparative Pharmacology and Toxicology 109 219-245.

Cavaco JE, van Blijswijk B, Leatherland JF, Goos HJ \& Schulz RW 1999 Androgen-induced changes in Leydig cell ultrastructure and steroidogenesis in juvenile African catfish, Clarias gariepinus. Cell and Tissue Research 297 291-299.

Cavaco JE, Bogerd J, Goos H \& Schulz RW 2001 Testosterone inhibits 11-ketotestosterone-induced spermatogenesis in African catfish (Clarias gariepinus). Biology of Reproduction 65 1807-1812.

Chang CF \& Lee YH 1992 Purification of the sex steroid-binding protein from common carp (Cyprinus carpio) plasma. Comparative Biochemistry and Physiology. B, Comparative Biochemistry 101 587-590.

Consten D, Lambert JG, Komen H \& Goos HJ 2002 Corticosteroids affect the testicular androgen production in male common carp (Cyprinus carpio L.). Biology of Reproduction 66 106-111.

Donaldson EM \& Hunter GA 1982 Sex control in fish with particular reference to salmonids. Canadian Journal of Fisheries and Aquatic Sciences 39 99-110.

DuBridge RB, Tang P, Hsia HC, Leong P-M, Miller JH \& Calos MP 1987 Analysis of mutation in human cells by using an Epstein-Barr virus shuttle system. Molecular and Cellular Biology 7 379-387.

Fitzpatrick MS, Gale WL \& Schreck CB 1994 Binding characteristics of an androgen receptor in the ovaries of coho salmon, Oncorhynchus kisutch. General and Comparative Endocrinology 95 399-408.
De Gendt K, Swinnen JV, Saunders PT, Schoonjans L, Dewerchin M, Devos A, Tan K, Atanassova N, Claessens F, Lecureuil C et al. 2004 A Sertoli cell-selective knockout of the androgen receptor causes spermatogenic arrest in meiosis. PNAS 101 1327-1332.

Graham FL \& van der Eb AJ 1973 A new technique for the assay of infectivity of human adenovirus 5 DNA. Virology 52 456-467.

Hannema SE \& Hughes IA 2007 Regulation of Wolffian duct development. Hormone Research 67 142-151.

Hossain MS, Larsson A, Scherbak N, Olsson PE \& Orban L 2008 Zebrafish androgen receptor: isolation, molecular, and biochemical characterization. Biology of Reproduction 78 361-369.

Van den Hurk R, Schoonen WGEJ, van Zoelen GA \& Lambert JGD 1987 The biosynthesis of steroid glucuronides in the testis of the zebrafish, Brachydanio rerio, and their pheromonal function as ovulation inducers. General and Comparative Endocrinology 68 179-188.

Ikeuchi T, Todo T, Kobayashi T \& Nagahama Y 1999 cDNA cloning of a novel androgen receptor subtype. Journal of Biological Chemistry 274 25205-25209.

Jørgensen A, Andersen O, Bjerregaard P \& Rasmussen LJ 2007 Identification and characterisation of an androgen receptor from zebrafish Danio rerio. Comparative Biochemistry and Physiology. Toxicology \& Pharmacology 146 561-568.

Kobayashi M, Aida K \& Stacey NE 1991 Induction of testis development by implantation of 11-ketotestosterone in female goldfish. Zoological Science 8 389-393.

Koldras M, Bieniarz K \& Kime DE 1990 Sperm production and steroidogenesis in testes of the common carp, Cyprinus carpio L., at different stages of maturation. Journal of Fish Biology 37 635-645.

Kusakabe M, Nakamura I, Evans J, Swanson P \& Young G 2006 Changes in mRNAs encoding steroidogenic acute regulatory protein, steroidogenic enzymes and receptors for gonadotropins during spermatogenesis in rainbow trout testes. Journal of Endocrinology 189 541-554.

Mayer I, Borg B \& Schulz RW 1990 Conversion of 11-ketoandrostenedione to 11-ketotestosterone by blood cells of six fish species. General and Comparative Endocrinology 77 70-74.

Miguel-Queralt S, Knowlton M, Avvakumov GV, Al-Nouno R, Kelly GM \& Hammond GL 2004 Molecular and functional characterization of sex hormone binding globulin in zebrafish. Endocrinology 145 5221-5230.

Mindnich R, Haller F, Halbach F, Moeller G, Hrabe de Angelis M \& Adamski J 2005 Androgen metabolism via $17 \beta$-hydroxysteroid dehydrogenase type 3 in mammalian and non mammalian vertebrates: comparison of the human and the zebrafish enzyme. Journal of Molecular Endocrinology 35 305-316.

Miura T \& Miura C 2001 Japanese eel: a model for analysis of spermatogenesis. Zoological Science 18 1055-1063.

Miura T, Yamauchi K, Takahashi H \& Nagahama Y 1991 Hormonal induction of all stages of spermatogenesis in vitro in the male Japanese eel (Anguilla japonica). PNAS 88 5774-5778.

Olsson PE, Berg AH, von Hofsten J, Grahn B, Hellqvist A, Larsson A, Karlsson J, Modig C, Borg B \& Thomas P 2005 Molecular cloning and characterization of a nuclear androgen receptor activity by 11 -ketotestosterone. Reproductive Biology and Endocrinology 337.

Pall MK, Mayer I \& Borg B 2002a Androgen and behavior in the male threespined stickleback, Gasterosteus aculeatus I. Changes in 11-ketotestosterone levels during the nesting cycle. Hormones and Behavior 41 377-383.

Pall MK, Mayer I \& Borg B 2002 b Androgen and behavior in the male threespined stickleback, Gasterosteus aculeatus II. Castration and 11-ketoandrostenedione effects on courtship and parental care during the nesting cycle. Hormones and Behavior 42 337-344.

Pasmanik M \& Callard G 1986 Characteristics of a testosterone-estradiol binding globulin (TEBG) in goldfish serum. Biology of Reproduction 35 838-845.

Rosenblum PM, Yamada L, Callard IP \& Callard GV 1985 Validation of radioimmunoassay systems for the measurement of 11-keto- and $11 \beta$ hydroxytestosterone in teleost blood. Comparative Biochemistry and Physiology. B, Comparative Biochemistry 82 659-665.

Sato T, Matsumoto T, Kawano H, Watanabe T, Uematsu Y, Sekine K, Fukuda T, Aihara K, Krust A, Yamada T et al. 2004 Brain masculinization requires androgen receptor function. PNAS 101 1673-1678. 
Schmidt PJ \& Idler DR 1962 Steroid hormones in the plasma of salmon at various stages of maturation. General and Comparative Endocrinology 2 204-214.

Schulz RW \& Miura T 2002 Spermatogenesis and its endocrine regulation. Fish Physiology and Biochemistry 26 43-56.

Schulz RW, van der Corput L, Janssen-Dommerholt J \& Goos HJTH 1994 Sexual steroids during puberty in male African catfish (Clarias gariepinus): serum levels and gonadotropin-stimulated testicular secretion in vitro. Journal of Comparative Physiology. B, Biochemical, Systemic, and Environmental Physiology 164 195-205.

Shan LX, Zhu LJ, Bardin CW \& Hardy MP 1995 Quantitative analysis of androgen receptor messenger ribonucleic acid in developing Leydig cells and Sertoli cells by in situ hybridization. Endocrinology 136 3856-3862.

Shiina H, Matsumoto T, Sato T, Igarashi K, Miyamoto J, Takemasa S, Sakari M, Takada I, Nakamura T, Metzger D et al. 2006 Premature ovarian failure in androgen receptor-deficient mice. PNAS 103 224-229.

Singh S \& Callard G 1992 Identification of an androgen receptor in the zonal testis of the salamander (Necturus maculosus). General and Comparative Endocrinology 86 220-230.

Soma KK 2006 Testosterone and agression: Berthold, birds and beyond. Journal of Neuroendocrinology $18543-551$.

Sperry TS \& Thomas P 1999 Characterization of two nuclear androgen receptors in Atlantic croaker: comparison of their biochemical properties and binding specificities. Endocrinology 140 1602-1611.

Stocklin E, Wissler M, Gouilleux F \& Groner B 1996 Functional interactions between Stat 5 and the glucocorticoid receptor. Nature 383 726-728.

Takeo J \& Yamashita S 2000 Rainbow trout androgen receptor- $\alpha$ fails to distinguish between any of the natural androgens tested in transactivation assay, not just 11-ketotestosterone and testosterone. General and Comparative Endocrinology 117 200-206.

Todo T, Ikeuchi T, Kobayashi T \& Nagahama Y 1999 Fish androgen receptor: cDNA cloning, steroid activation of transcription in transfected mammalian cells, and tissue mRNA levels. Biochemical and Biophysical Research Communications 254 378-383.
Vermeulen GJ, Lambert JGD, van der Looy MJW \& Goos HJTH 1994 Gas chromatographic-mass spectrometric (GC-MS) analysis of gonadal steroids in plasma of the male African catfish, Clarias gariepinus: effects of castration or treatment with gonadotropin releasing hormone analogue. General and Comparative Endocrinology 96 288-297.

Vischer HF, Teves AC, Ackermans JC, van Dijk W, Schulz RW \& Bogerd J 2003 Cloning and spatiotemporal expression of the follicle-stimulating hormone $\beta$ subunit complementary DNA in the African catfish (Clarias gariepinus). Biology of Reproduction 68 1324-1332.

Wang XG \& Orban L 2007 Anti-müllerian hormone and 11 $\beta$-hydroxylase show reciprocal expression to that of aromatase in the transforming gonad of zebrafish males. Developmental Dynamics 236 1329-1338.

Weltzien FA, Kobayashi T, Andersson E, Norberg B \& Andersen Ø 2003 Molecular characterization and expression of FSH $\beta, \mathrm{LH} \beta$, and common $\alpha$-subunit in male Atlantic halibut (Hippoglossus hippoglossus). General and Comparative Endocrinology 131 87-96.

Westerfield M 2000 The Zebrafish Book. A Guide for the Laboratory Use of Zebrafish (Danio rerio), 4th edn. Eugene: University of Oregon Press.

Wilson VS, Cardon MC, Thornton J, Korte JJ, Ankley GT, Welch J, Gray LE Jr \& Hartig PC 2004 Cloning and in vitro expression and characterization of the androgen receptor and isolation of estrogen receptor $\alpha$ from the fathead minnow (Pimephales promelas). Environmental Science \& Technology 38 6314-6321.

Received 4 February 2008

First decision 25 February 2008

Revised manuscript received 29 April 2008

Accepted 8 May 2008 